\title{
AC 2008-706: CREATING A SOLAR OVEN INDUSTRY IN TANZANIA: A CAPSTONE DESIGN EXPERIENCE
}

\section{Craig Somerton, Michigan State University}

CRAIG W. SOMERTON Craig W. Somerton is an Associate Professor and Associate Chair of the Undergraduate Program for Mechanical Engineering at Michigan State University. He teaches in the area of thermal engineering including thermodynamics, heat transfer, and thermal design. He also teaches the capstone design course for the department. Dr. Somerton has research interests in computer design of thermal systems, transport phenomena in porous media, and application of continuous quality improvement principles to engineering education. He received his B.S. in 1976, his M.S. in 1979, and his Ph.D. in 1982, all in engineering from UCLA. 


\title{
Creating a Solar Oven Industry in Tanzania: A Capstone Design Experience
}

\begin{abstract}
$\underline{\text { Abstract }}$
Tanzania is one of the poorest countries in the world. The primary method of cooking is open, wood-burning fires. This approach has lead to major environmental, health, and societal problems, examples of which include deforestation and respiratory illnesses. At a latitude of $7^{\circ} \mathrm{S}$, Tanzania receives a consistently high level of solar energy. It seems apparent that the use of solar energy in cooking could be a potential solution to these problems.
\end{abstract}

For approximately five years, a non-profit organization, Solar Circle, has been working to develop solar cooking as a feasible alternative to word-burning cooking in Southern Tanzania. The mechanical engineering capstone design class at XXX University was approached to provide technical assistance in this development. Two design teams, one from the fall semester and one from the spring semester took on the challenge of designing a solar oven for Tanzania that could be built with materials and techniques available in Africa. As part of this experience the teams spent two weeks in Tanzania building an understanding of the culture and people, as well as building and testing four prototype ovens.

This will paper will address how such a design project was undertaken including details of the modeling and easing analysis, the manufacturing process, and the lessons learned in taking a taking a group of engineering students to Africa. 